\title{
Protective effect of microRNA-340-5p against oxygen-glucose deprivation/reperfusion in PC12 cells through targeting neuronal differentiation 4
}

\author{
JUAN WANG and GANZHE LIU \\ Department of Neurology, The Central Hospital of Wuhan, Wuhan, Hubei 430014, P.R. China
}

Received November 25, 2019; Accepted April 17, 2020

DOI: $10.3892 / \mathrm{mmr} .2020 .11174$

\begin{abstract}
The expression levels of microRNA (miR)-340-5p are reportedly decreased in the peripheral blood during acute ischemic stroke; however, the direct effect and mechanism of action of miR-340-5p in ischemic stroke remains largely unknown. The present study aimed to investigate the effects of miR-340-5p, and its mechanism of action, on PC12 cells following oxygen-glucose deprivation/reperfusion (OGD/R) induction. OGD/R-induced PC12 cells served as the cellular model and subsequently, mRNA expression levels of miR-340-5p and neuronal differentiation 4 (Neurod4) were analyzed using reverse transcription-quantitative PCR. Tumor necrosis factor- $\alpha$, interleukin (IL) $-1 \beta$ and IL- 6 expression levels were detected using ELISA kits, and flow cytometry was used to determine the rate of cellular apoptosis. In addition, a nitric oxide (NO) synthase activity assay kit was used to detect NO levels and a NADPH assay kit was used to measure NADPH levels. Western blotting was also performed to analyze protein expression levels of bax, bcl-2, cleaved caspase 3 and phosphorylated endothelial NOS (eNOS), and the target gene of miR-340-5p was predicted using TargetScan software and verified using a dual-luciferase reporter assay. The expression levels of miR-340-5p were decreased in PC12 cells following OGD/R induction and Neurod4 was identified as a target gene of miR-340-5p. In addition, miR-340-5p overexpression reduced inflammation, apoptotic rate, NO production and NADPH levels, in addition to increasing eNOS expression in PC12 cells following OGD/R induction. Notably, the overexpression of Neurod4 reversed the aforementioned effects of miR-340-5p on PC12 cells following $\mathrm{OGD} / \mathrm{R}$ induction. In conclusion, the findings of the present study suggested that miR-340-5p may protect PC12 cells against OGD/R through targeting Neurod4, which
\end{abstract}

Correspondence to: Mr. Ganzhe Liu, Department of Neurology, The Central Hospital of Wuhan, 26 Shengli Street, Hankou, Wuhan, Hubei 430014, P.R. China

E-mail: ganzheliuwh1@163.com

Key words: microRNA-340-5p, neuronal differentiation 4, oxygenglucose deprivation/reperfusion, inflammation, apoptosis could provide important implications for the treatment of ischemia-reperfusion injury based on miR-340-5p expression levels in vivo.

\section{Introduction}

Ischemic stroke is one of the most frequently occurring conditions among older populations, accounting for a large proportion of the morbidity and mortality rates worldwide $(1,2)$. Smoking habits, hypertension and diabetes have all been listed as risk factors of ischemic stroke $(3,4)$. Ischemic stroke occurs following a blockage in an artery leading to the brain; thus, an insufficient supply of oxygen and glucose reaches the brain that is required for cellular energy, which culminates in irreparable damage $(5,6)$. Currently, there are no effective approved treatments for ischemic stroke (7). Patients are normally treated with recombinant tissue plasminogen activator, undergo surgical excision of the obstruction in the blood vessel or are prescribed protective treatments following stroke, such as fire-needle acupuncture (8). During treatment, the limited reperfusion time window and rapid blood reperfusion cause secondary injuries, namely reperfusion injury, including hemorrhagic transformation and reactive oxygen species (ROS)-induced injuries (9); thus, current treatment regimens are not ideal. Despite significant research being conducted on ischemia-reperfusion injury, little progress has been made. Therefore, it remains an urgent requirement to investigate effective treatment targets and determine the mechanism of action of ischemia-reperfusion injury.

MicroRNAs (miRNAs/miRs) are single-stranded, non-coding RNAs 22 nucleotides in length, which can silence gene expression through transiently promoting translational arrest or inducing the degradation of mRNA (10). Previous studies have reported that miRNAs are involved in the pathophysiology of ischemic stroke through suppressing post-stroke angiogenesis, inhibiting oxidative stress, reducing neuronal loss, suppressing inflammation and preventing excitotoxic injury (11-14).

Notably, miR-340-5p has been observed to relieve chronic constriction injury-induced neuropathic pain and decrease the inflammatory response (15). miR-340-5p has also been demonstrated to suppress hypoxia/reoxygenation-induced apoptosis and oxidative stress in cardiomyocytes (16). Oxidative stress and inflammation are the main causes 
of cerebral ischemia-reperfusion injury, which has been established through numerous previous studies (17-21). For example, in one previous study, miR-340-5p was found to inhibit inflammation and oxidative stress in cardiomyocytes and serve a role in cerebral ischemia-reperfusion injury (16). Furthermore, it was reported that miR-340-5p expression levels were decreased in the peripheral blood following acute ischemic stroke (22), which suggested that miR-340-5p may serve a vital role in ischemic stroke treatment. Based on these previous studies, the present study aimed to investigate the effects of miR-340-5p on a commonly used cell model of ischemia-reperfusion injury, oxygen-glucose deprivation/reperfusion (OGD/R)-induced PC12 cells (23-25). The target gene of miR-340-5p was also investigated.

\section{Materials and methods}

Cell culture and OGD/R induction. PC12 cells (CRL-1721.1) were obtained from the American Type Culture Collection and were seeded into 96 -well plates at a density of $1 \times 10^{4}$ cells/well. Cells were cultured in RPMI-1640 medium (Sigma-Aldrich; Merck KGaA), supplemented with 10\% FBS (Gibco; Thermo Fisher Scientific, Inc.) and $1 \%$ penicillin/streptomycin, and maintained in a humidified atmosphere with $5 \% \mathrm{CO}_{2}$ at $37^{\circ} \mathrm{C}$. To study the effects of microRNA-340-5p, the cells were divided into the control group, OGD/R group, miR-NC group and miR-340-5p mimic group. For further study on the underlying mechanism, the cells were divided into an OGD/R group, miR-NC group, miR-340-5p mimic group, miR-340-5p mimic + empty plasmid group and a miR-340-5p mimic + Neurod4 overexpression group. OGD/R was performed in all the groups except for control groups.

$\mathrm{OGD} / \mathrm{R}$ was performed by culturing the cells in glucose-free medium (RPMI-1640; Gibco; Thermo Fisher Scientific, Inc.) in an incubator with $\mathrm{CO}_{2}\left(5 \%\right.$; v/v) and $\mathrm{N}_{2}\left(95 \%\right.$; v/v) at $37^{\circ} \mathrm{C}$. After $2 \mathrm{~h}$ of incubation, the medium was replaced with normal medium and cells were incubated in an atmosphere of $5 \% \mathrm{CO}_{2}$ and $95 \%$ air at $37^{\circ} \mathrm{C}$ for $12 \mathrm{~h}$.

Cell transfection. Cells were cultured in 6-well plates ( $1 \times 10^{4}$ cells/well) containing RPMI-1640 medium without antibiotics. Upon reaching $70 \%$ confluence, cells were transfected with a miR-340-5p mimic, miR-negative control (NC), neuronal differentiation 4 (Neurod4) pcDNA3.1 plasmid $(10 \mu \mathrm{l} / \mathrm{ml})$ or an empty pcDNA3.1 plasmid $(10 \mu \mathrm{l} / \mathrm{ml})$ using Lipofectamine ${ }^{\circledR} 2000$ reagent (Invitrogen; Thermo Fisher Scientific, Inc.) under serum-free conditions for $6 \mathrm{~h}$. After $48 \mathrm{~h}$ of transfection, the cells were collected for subsequent experiments. The miR-340-5p mimic (5'-UUAUAA AGC AAUGAGACUGAUU-3'), miR-NC (5'-UUCUCCGAACGU GUCACGUTT-3'), pcDNA3.1 empty plasmid and Neurod4 overexpression plasmid were all purchased from Shanghai GenePharma Co., Ltd.

Reverse transcription-quantitative PCR (RT-qPCR). Total RNA was extracted from cells using TRIzol ${ }^{\circledR}$ reagent (Invitrogen; Thermo Fisher Scientific, Inc.). Total RNA was reverse transcribed into cDNA using the qScript miRNA cDNA Synthesis kit (Quantabio), according to the manufacturer's protocol. qPCR was subsequently performed using a TaqMan ${ }^{\mathrm{TM}}$ Real Time PCR Mix (Thermo Fisher Scientific, Inc.). The following primer pairs were used for qPCR: GAPDH forward, 5'-AATGGATTTGGACGCATTGGT-3' and reverse, 5'-TTTGCACTGGTACGTGTTGAT-3'; U6 forward, 5'-CTCGCTTCGGCAGCACA-3' and reverse, 5'-AACGCTTCACGAATTTGCGT-3'; Neurod4 forward, 5'-AGCTGGTCAACACACAATCCT-3' and reverse, 5'-TTCCATAAGAGCCCGGTCTTC-3'; and miR-340-5p forward, 5'-GCGGTTATAAAGCAATGAGA-3' and reverse, 5'-GTGCGTGTCGTGGAGTCG-3'. The following thermocycling conditions were used for qPCR: Initial denaturation at $95^{\circ} \mathrm{C}$ for $8 \mathrm{~min}$; followed by 40 cycles at $95^{\circ} \mathrm{C}$ for $15 \mathrm{sec}$ and $60^{\circ} \mathrm{C}$ for $30 \mathrm{sec}$; and a final extension at $70^{\circ} \mathrm{C}$ for $35 \mathrm{sec}$. Expression levels were quantified using the $2^{-\Delta \Delta \mathrm{Cq}}$ method (26) and normalized to GAPDH or U6.

Detection of tumor necrosis factor (TNF)-a, interleukin (IL)-1 $\beta$, monocyte chemoattractant protein-1 (MCP-1) and IL-6. TNF- $\alpha$ (cat. no. BMS662), IL-1 $\beta$ (cat. no. ERIL1B), MCP-1 (cat. no. BMS631INST) and IL-6 (cat. no. BMS625) ELISA kits (Thermo Fisher Scientific, Inc.) were used to detect the levels of TNF- $\alpha$, IL-1 $\beta$, MCP-1 and IL-6. Briefly, cells in the different groups were lysed in lysis buffer (Beyotime Institute of Biotechnology) and centrifuged (16,000 x g for $10 \mathrm{~min}$ at $4^{\circ} \mathrm{C}$ ) to collect the supernatants. The levels of TNF- $\alpha$, IL-1 $\beta$, MCP-1 and IL- 6 in the supernatants of each group were analyzed using the corresponding kits, according to the manufacturer's protocols.

Flow cytometric analysis of apoptosis. Flow cytometry was used to analyze the effects of miR-340-5p overexpression on cell apoptosis with an Annexin V-FITC Apoptosis Detection kit (eBioscience; Thermo Fisher Scientific, Inc.). Cells were grouped into a control group, OGD/R group, miR-NC group and miR-340-5p mimic group. To determine the effects of the target binding between Neurod4 and miR-340-5p on the rate of cell apoptosis, the cells were divided into an OGD/R group, miR-NC group, miR-340-5p mimic group, miR-340-5p mimic + empty plasmid group and a miR-340-5p mimic + Neurod4 overexpression group. OGD/R was performed in all the groups except for control group. Following their respective treatments, cells $\left(1 \times 10^{5}\right.$ cells/well) in the different groups were washed with PBS and resuspended in the binding buffer. Cells were subsequently incubated with $5 \mu \mathrm{l}$ Annexin V-FITC and $10 \mu \mathrm{l}$ propidium iodide staining solution for $15 \mathrm{~min}$ at room temperature in the dark. Apoptotic cells were analyzed using a BD FACSCalibur ${ }^{\mathrm{TM}}$ flow cytometer (BD Biosciences) and BD CellQuest software (version 5.1; BD Biosciences).

Measurement of nitric oxide (NO)/NADPH levels. The levels of $\mathrm{NO}$ and NADPH were analyzed using a Nitric Oxide Synthase Activity assay kit (colorimetric; cat. no. ab211083; Abcam) and NADPH assay kit (colorimetric; cat. no. ab186031; Abcam), respectively. Briefly, cells in the different groups were lysed in lysis buffer (Beyotime Institute of Biotechnology) and collected prior to being analyzed for the levels of NO and NADPH using their corresponding kits, according to the manufacturer's protocols. 
Western blotting. Protein expression levels were analyzed using western blotting. Total protein was extracted from cells using lysis buffer (Beyotime Institute of Biotechnology) and lysates were centrifuged $\left(16,000 \mathrm{xg}\right.$ for $10 \mathrm{~min}$ at $\left.4^{\circ} \mathrm{C}\right)$. Total protein was quantified using a bicinchoninic acid assay kit [Yeasen Biotechnology (Shanghai) Co., Ltd.] and proteins (30 $\mu \mathrm{g} /$ lane) were separated via SDS-PAGE on a $10 \%$ gel. The separated proteins were transferred to PVDF membranes (EMD Millipore) and blocked in 5\% skimmed milk for $2 \mathrm{~h}$ at room temperature. The membranes were incubated at $4^{\circ} \mathrm{C}$ overnight with the following primary antibodies: Anti-Bcl-2 (1:1,000; cat. no. ab196495; Abcam), anti-Bax (1:1,000; cat. no. ab3250; Abcam), anti-Bad (1:1,000; cat. no. ab32445; Abcam), anti-cleaved caspase 3 (1:1,000; cat. no. ab49822; Abcam), anti-caspase 3 (1:1,000; cat. no. ab13847; Abcam), anti-phosphorylated (p)-endothelial NOS (eNOS; 1:500; cat. no. ab215717; Abcam), anti-eNOS (1:500; cat. no. ab199956; Abcam) and anti-GADPH (1:500; cat. no. ab9485; Abcam). Following the primary antibody incubation, the membranes were incubated with a horseradish peroxidase-conjugated secondary antibody (1:5,000; cat. no. ab7090; Abcam) for $1 \mathrm{~h}$ at room temperature. Protein bands were visualized using an ImageQuant ${ }^{\mathrm{TM}}$ LAS 500 (GE Healthcare) and an ECL western blotting substrate kit (cat. no. ab65623; Abcam). ImageQuant TL software (version 7.0; Cytiva) was used to perform densitometry.

Dual-luciferase reporter assay. Neurod4 was predicted as a target gene of miR-340-5-5p using TargetScan software (version 7.2; http://www.targetscan.org/vert_72/). Thus, a dual-luciferase reporter assay was performed to verify the target binding of miRNA-340-5p and Neurod4. The wild-type (WT) 3' untranslated region (3'UTR) binding site of Neurod4 was amplified using PCR and cloned into a pmirGLO reporter plasmid (Promega Corporation). The 3'UTR fragment of Neurod4 was also mutated, resulting in a mutant (MUT) 3'UTR, using the Fast MultiSite Mutagenesis System (Beijing Transgen Biotech Co., Ltd.) and cloned into the pmirGLO reporter plasmid. Cells $\left(5 \times 10^{4}\right)$ cultured in 24-well plates were co-transfected with an equal concentration (450 ng/ $\mu \mathrm{l}$ ) of Neurod4 (WT or MUT) and miR-340-5p mimic or miR-NC using Lipofectamine ${ }^{\circledR} 2000$ (Invitrogen; Thermo Fisher Scientific, Inc.), according to the manufacturer's protocols. After transfection for $48 \mathrm{~h}$, the relative luciferase activity was detected using a Dual-Luciferase Reporter assay system (Promega Corporation), according to the manufacturer's protocols. Luciferase activity was normalized to Renilla luciferase activity.

Statistical analysis. Statistical analysis was performed using GraphPad Prism 5.0 software (GraphPad Software, Inc.) and data from three independent experiments are presented as the mean \pm SD. Statistical differences were determined using a one-way ANOVA, followed by Tukey's multiple comparison test. $\mathrm{P}<0.05$ was considered to indicate a statistically significant difference.

\section{Results}

miR-340-5p expression levels are decreased in the $O G D / R$ group and miR-340-5p overexpression reduces the
$O G D / R$-induced inflammatory status. The expression levels of miR-340-5p were significantly reduced in the OGD/R group compared with the control group (Fig. 1A), indicating that miR-340-5p may have a certain role in OGD/R-induced cells. The miR-340-5p mimic was successfully transfected into OGD/R-induced cells; significantly increased expression levels of miR-340-5p were observed in the miR-340-5p mimic group compared with the OGD/R and miR-NC groups (Fig. 1B). Subsequently, the effects of miR-340-5p overexpression on the inflammatory status of cells were investigated. Compared with the control group, the levels of TNF- $\alpha$, IL- $1 \beta$, MCP-1 and IL- 6 were all significantly increased in the OGD/R group (Fig. 1C), which demonstrated that the OGD/R cell model was successfully induced. The OGD/R-induced inflammatory status, which is indicated by the levels of TNF- $\alpha$, IL- $1 \beta$, MCP- 1 and IL-6, was decreased in the miR-340-5p mimic group when compared with the OGD/R group (Fig. 1C).

miR-340-5p overexpression reduces the cell apoptotic rate induced by $O G D / R$ in PC12 cells. The rate of cell apoptosis in the OGD/R group was significantly increased compared with the control group (Fig. 2A and B), which further confirmed that the OGD/R cell model was successfully induced. However, OGD/R-induced apoptosis was significantly reduced by the miR-340-5p mimic. To further validate these findings, the expression levels of apoptotic proteins were analyzed. The expression levels of the anti-apoptotic protein Bcl-2 were significantly decreased following OGD/R induction compared with the control group, whereas OGD/R-induced decreases in the Bcl-2 expression levels were significantly increased in the miR-340-5p mimic group (Fig. 3). Furthermore, the expression levels of pro-apoptotic proteins, Bax and cleaved caspase $3 /$ caspase 3 , were significantly increased in the OGD/R group compared with the control group, and this effect was significantly reduced following miR-340-5p overexpression (Fig. 3). All these findings suggested that miR-340-5p overexpression may inhibit cell apoptosis through increasing the expression levels of Bcl-2, and decreasing those of Bax, cleaved caspase 3 and caspase 3 .

miR-340-5p overexpression inhibits NO production, reduces $N A D P H$ levels and increases the relative expression levels of p-eNOS in OGD/R-induced PC12 cells. The relative expression levels of $\mathrm{p}$-eNOS were determined as the ratio of p-eNOS/eNOS/GADPH. NO, which is induced by OGD/R in $\mathrm{PC} 12$ cells, was evaluated herein. The NO levels were significantly increased in the OGD/R group compared with the control group, whereas these OGD/R-induced increased levels were significantly reduced in the miR-340-5p mimic group (Fig. 4A). Furthermore, p-eNOS/eNOS was significantly decreased in the OGD/R group compared with the control group, and this effect was partly reversed in the miR-340-5p mimic group (Fig. 4C and D). NADPH is an important indicator of the presence of oxidative stress, which generates ROS (27). OGD/R-induced increases in NADPH levels were significantly reduced by miR-340-5p overexpression (Fig. 4B). All these results indicated that miR-340-5p overexpression may exert a protective effect over OGD/R-induced PC12 cells through increasing eNOS activity, and reducing NADPH levels and NO production. 
A
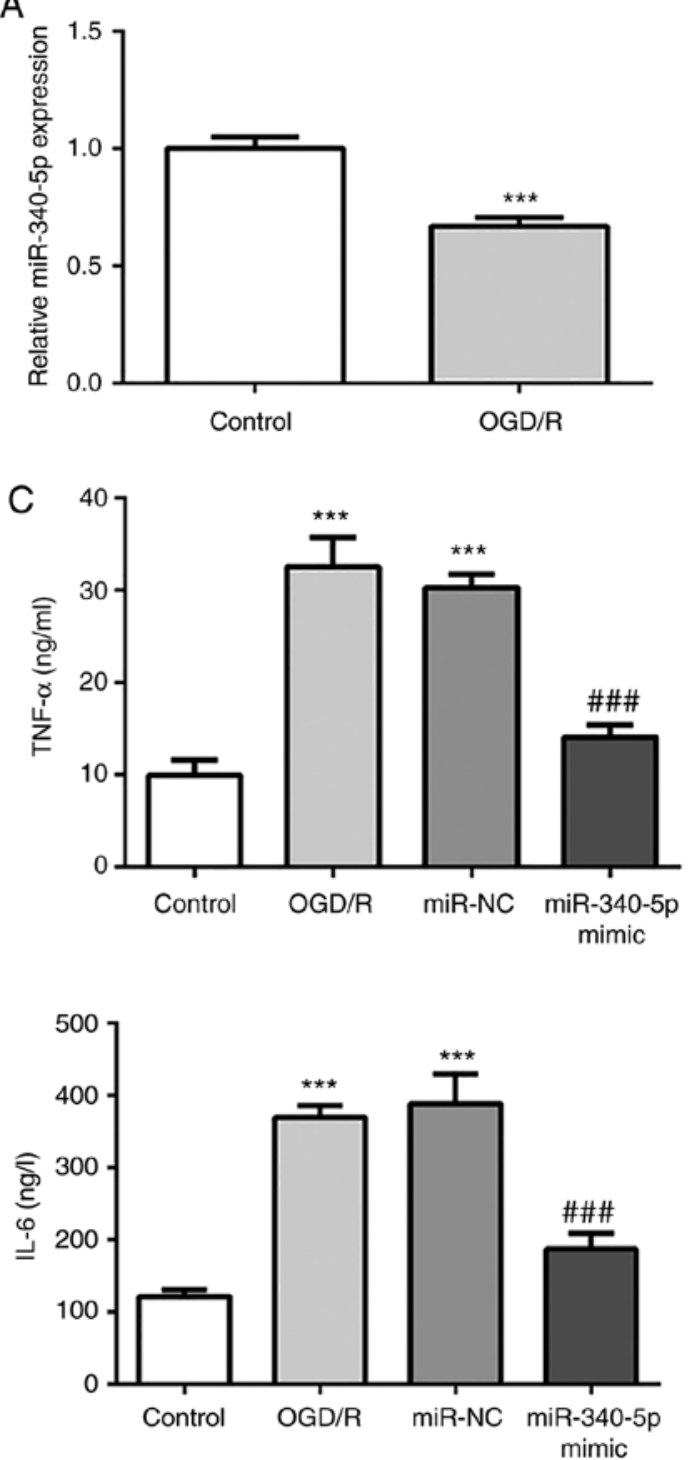

B
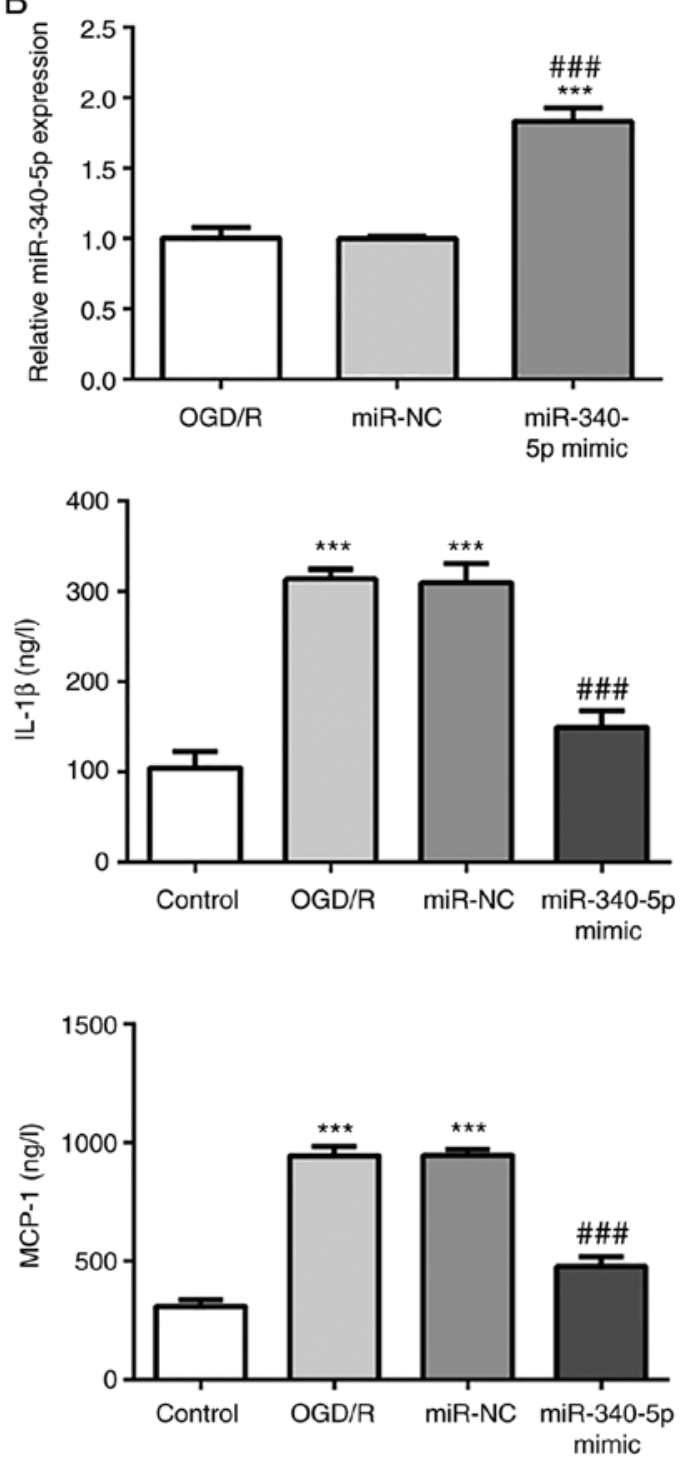

Figure 1. miR-340-5p expression levels are increased in the OGD/R group and the effect of miR-340-5p overexpression on the inflammatory status. Expression levels of miR-340-5p in the (A) control and OGD/R groups, and (B) OGD/R, miR-NC and miR-340-5p mimic groups (C) Levels of TNF- $\alpha$, IL-1 13 , MCP-1 and IL-6 were analyzed in the different groups. ${ }^{* * *} \mathrm{P}<0.001$ vs. control or miR-NC group; ${ }^{\# \# \# ~} \mathrm{P}<0.001 \mathrm{vs.} \mathrm{OGD/R}$ group. IL, interleukin; MCP-1, monocyte chemoattractant protein-1; miR, microRNA; NC, negative control; OGD/R, oxygen-glucose deprivation/reperfusion; TNF- $\alpha$, tumor necrosis factor $\alpha$.

Neurod4 is a target of miR-340-5p in OGD/R-induced PC12 cells. It was predicted by TargetScan that Neurod4 was a target gene of miR-340-5p (Fig. 5A), thus a dual-luciferase reporter assay was used for further validation. The relative luciferase activity was significantly reduced in the 3'UTR-WT- Neurod4 + miR-340-5p mimic group compared with the 3'UTR-MUT-Neurod4 + miR-340-5p mimic group (Fig. 5B), indicating that miR-340-5p may target Neurod4 in OGD/R-induced PC12 cells. Furthermore, Neurod4 expression levels were significantly increased in the OGD/R group compared with the control group, and this effect was significantly reversed following the addition of the miR-340-5p mimic (Fig. 5C). This observation further validated that Neurod4 may be a target of miR-340-5p in OGD/R-induced PC12 cells.

miR-340-5p overexpression reduces the inflammatory status, whereas Neurod4 overexpression counteracts the effects of miR-340-5p overexpression on OGD/R-induced PC12 cells.
Neurod4 expression levels were significantly increased in the Neurod4 overexpression group compared with the empty plasmid group (Fig. 6A), indicating that Neurod4 overexpression was successful in the PC12 cells. The OGD/R-induced levels of TNF- $\alpha$, IL-1 $\beta$, MCP- 1 and IL- 6 were significantly reduced following miR-340-5p overexpression in the OGD/R + miR-340-5p mimic group (Fig. 6B-E). However, following Neurod4 overexpression, the anti-inflammatory effects of miR-340-5p overexpression on OGD/R-induced PC12 cells were reversed and the inflammatory levels were significantly increased. These findings indicated that the anti-inflammatory effects of miR-340-5p overexpression on OGD/R-induced PC12 cells may be achieved by decreasing the levels of TNF- $\alpha$, IL-1 $\beta$, MCP-1 and IL- 6 through downregulating Neurod4 expression.

miR-340-5p overexpression reduces apoptosis and Neurod4 overexpression counteracts the effects of miR-340-5p 

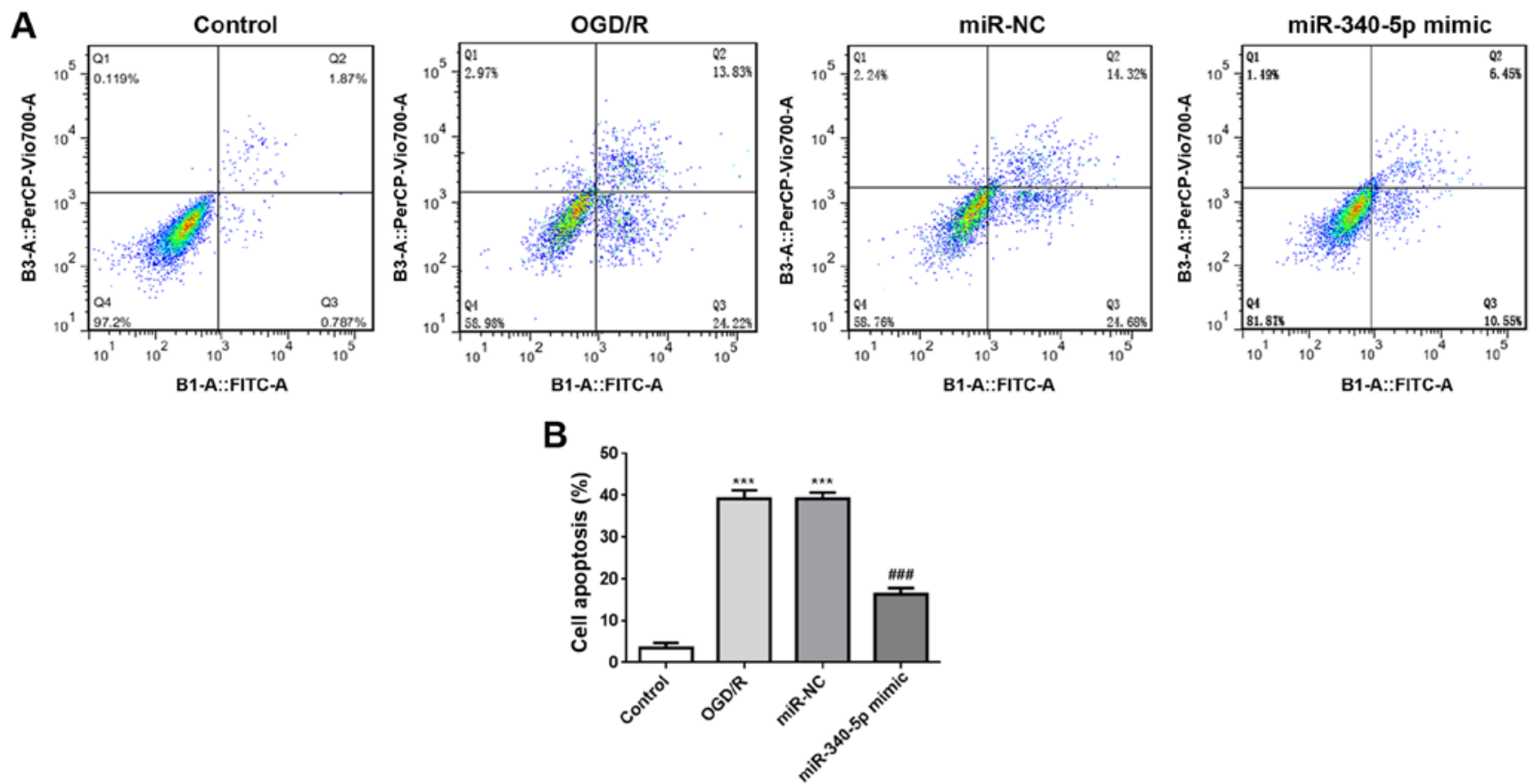

Figure 2. Effects of miR-340-5p overexpression on cell apoptosis. (A) Flow cytometric analysis of apoptosis was performed and (B) semi-quantified to detect the apoptotic rate of $\mathrm{PC} 12$ cells in different groups. ${ }^{* * *} \mathrm{P}<0.001$ vs. control group; ${ }^{\# \# \#} \mathrm{P}<0.001$ vs. OGD/R group. miR, microRNA; NC, negative control; OGD/R, oxygen-glucose deprivation/reperfusion.
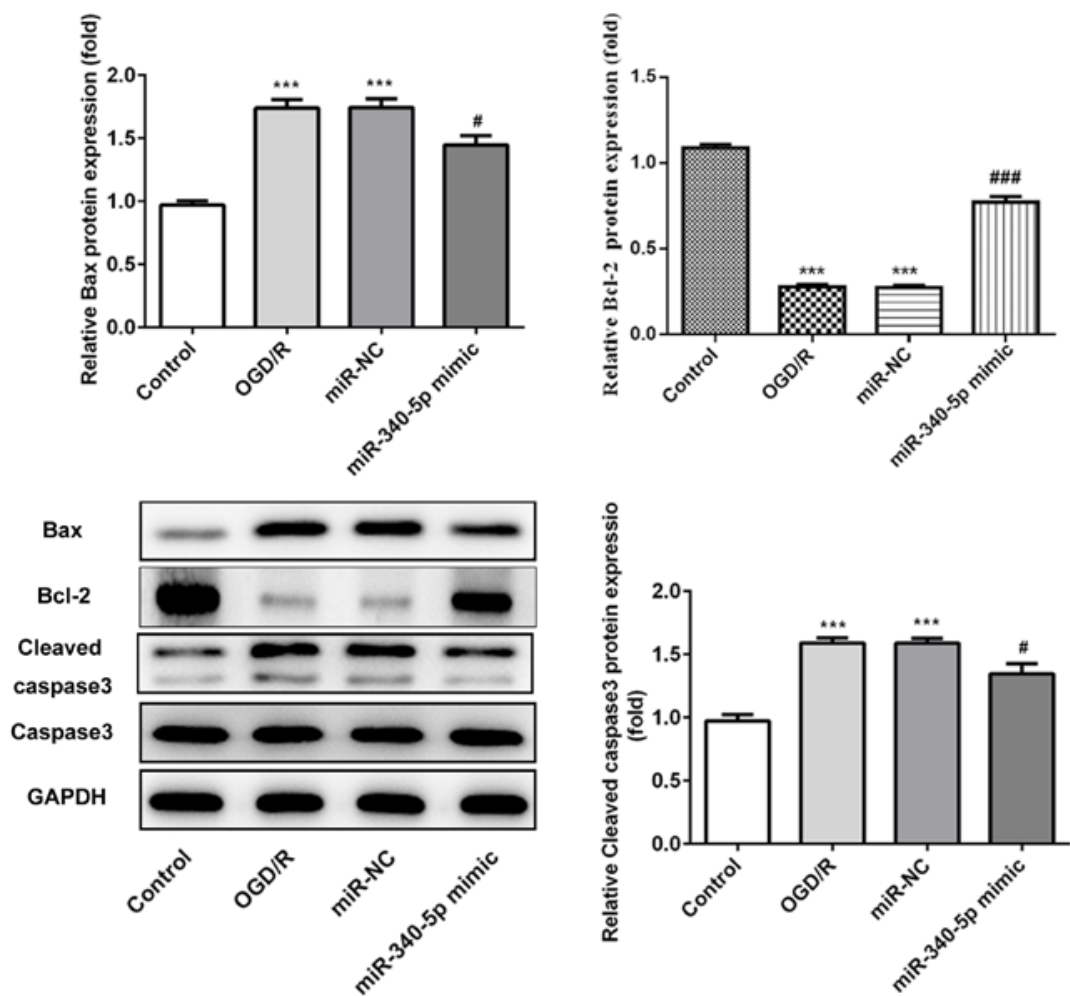

Figure 3. Effect of miR-340-5p overexpression on apoptosis-related proteins. The expression levels of Bax, Bcl-2, cleaved caspase 3 and cleaved caspase 3 were detected in the different groups. ${ }^{* * *} \mathrm{P}<0.001$ vs. control group; ${ }^{~} \mathrm{P}<0.05,{ }^{\# \# \#} \mathrm{P}<0.001$ vs. miR-NC group. miR, microRNA; OGD/R, oxygen-glucose deprivation/reperfusion; NC, negative control.

overexpression on $O G D / R$-induced PC12 cells. The OGD/R-induced increases in cell apoptosis were significantly reduced following miR-340-5p overexpression (Fig. 7A and B); however, the apoptotic rate in OGD/R-induced cells transfected with the miR-340-5pmimic was significantly increased following Neurod 4 overexpression. These findings suggested that Neurod 4 overexpression may reverse the effects of miR-340-5p overexpression on cell apoptosis in OGD/R-induced $\mathrm{PC} 12$ cells. As an 


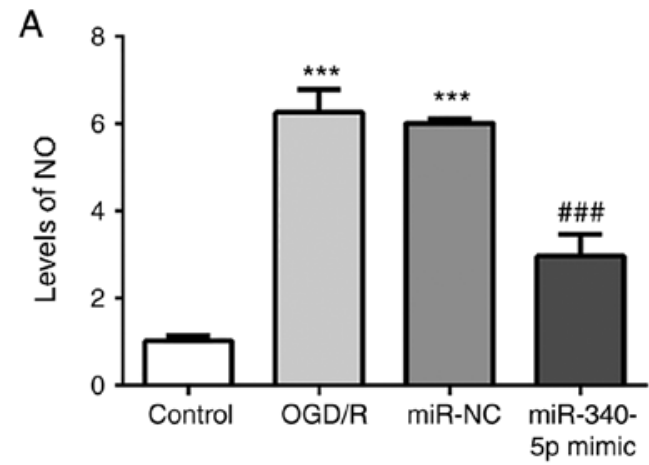

C

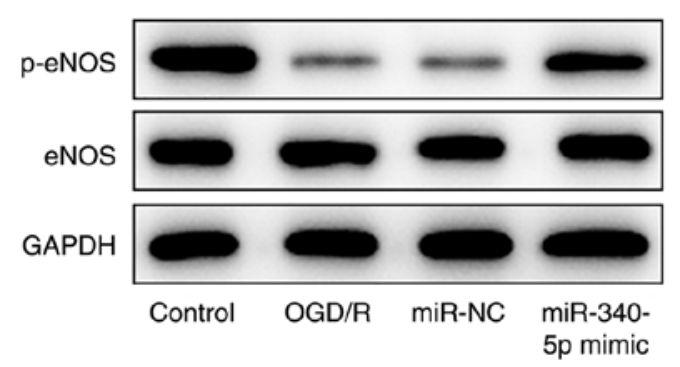

B
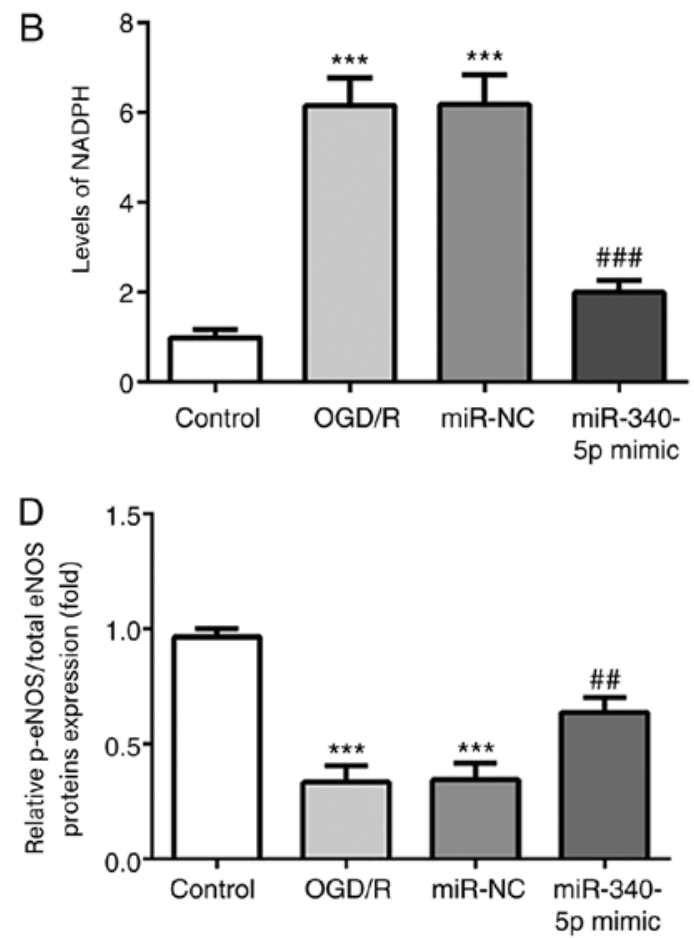

Figure 4. Effect of miR-340-5p overexpression on the levels of NO, NADPH and p-eNOS/eNOS. (A) Levels of NO and (B) NADPH, and (C) expression levels of $\mathrm{p}$-eNOS/eNOS were detected in the different groups. (D) Semi-quantification of western blotting. ${ }^{* * * *} \mathrm{P}<0.001$ vs. control group; ${ }^{\# \#} \mathrm{P}<0.01,{ }^{\# \# \#} \mathrm{P}<0.001$ vs. miR-NC group. eNOS, endothelial nitric oxide synthase; miR, microRNA; NC, negative control; NO, nitric oxide; OGD/R, oxygen-glucose deprivation/reperfusion; p, phosphorylated.

\section{A}

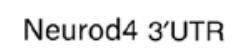

hsa-miR-340-5p

$3^{\prime}$

B

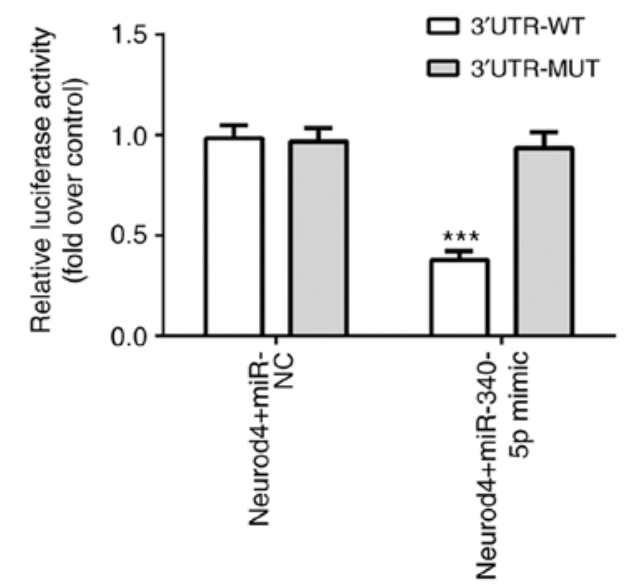

GAAAUAUC

...ACAUUGCAUUGAUUUCUUUAUAG...

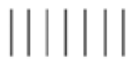

UUAGUCAGAGUAACGAAAUAUU

Figure 5. Verifying the target gene of miR-340-5p in OGD/R-induced PC12 cells. (A) Neurod4 was identified as the target gene of miR-340-5p using TargetScan software. (B) Dual-luciferase reporter assay was performed in the different groups and the mutated sequence is indicated by the red font. (C) Neurod4 expression levels were determined in the different groups. ${ }^{* * *} \mathrm{P}<0.001$ vs. control group; ${ }^{\# \# \#} \mathrm{P}<0.001$ vs. miR-NC group. miR, microRNA; MUT, mutant; NC, negative control; Neurod4, neuronal differentiation 4; OGD/R, oxygen-glucose deprivation/reperfusion; UTR, untranslated region; WT, wild-type.

anti-apoptotic protein, Bcl-2 expression levels were observed to be significantly increased in the OGD/R + miR-340-5p mimic group; however, this effect was reversed following Neurod4 overexpression (Fig. 7C). In addition, the expression levels of the pro-apoptotic proteins Bax, Bad, cleaved caspase 3 and caspase 3 demonstrated the opposite trend compared with the
Bcl-2 expression levels in each group. Taken together, these findings suggested that miR-340-5p overexpression may protect OGD/R-induced cells from apoptosis through increasing the expression levels of $\mathrm{Bcl}-2$, and decreasing the expression levels of Bax, Bad, cleaved caspase 3 and caspase 3 through decreasing Neurod4 expression. 

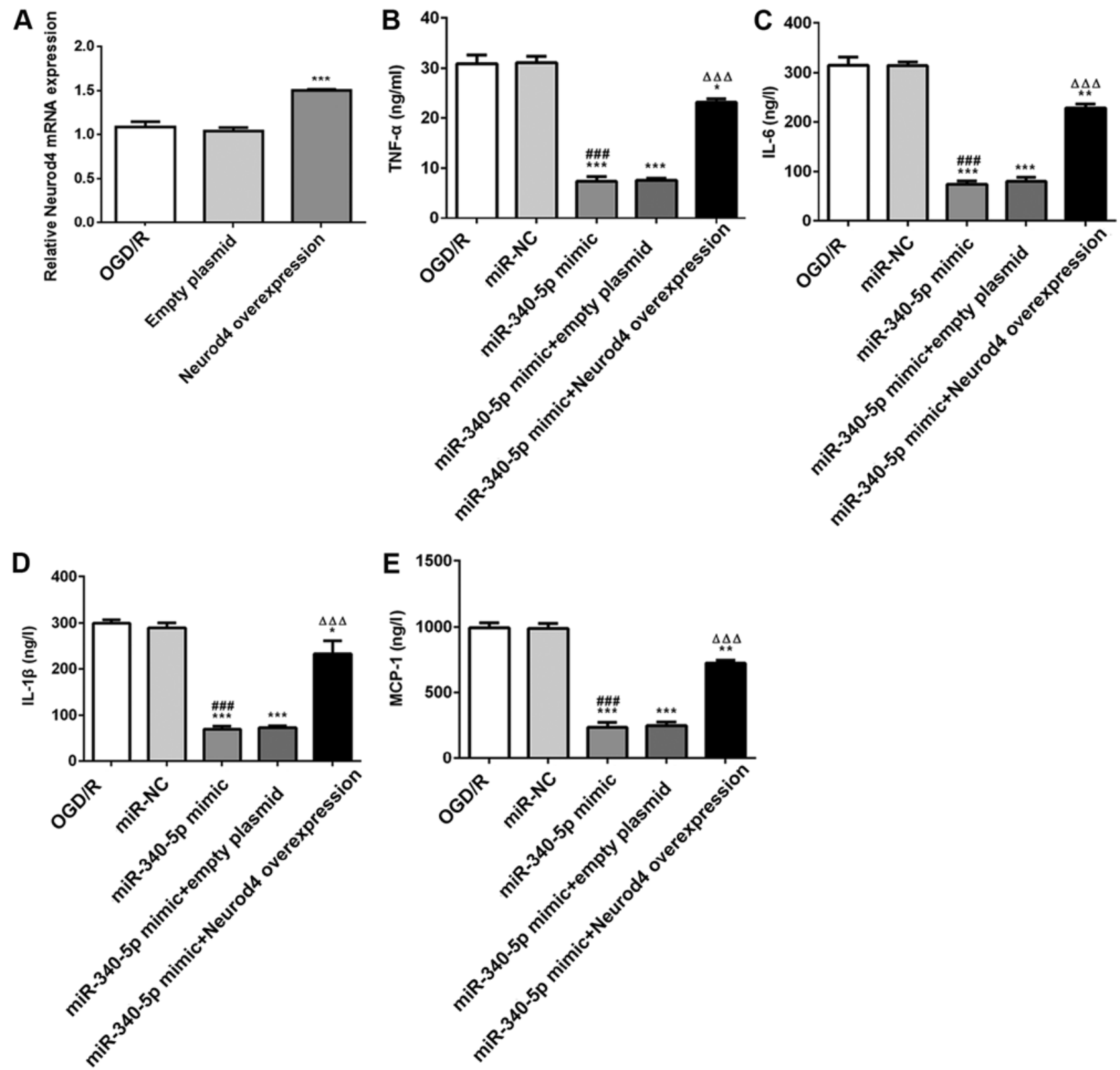

Figure 6. Neurod4 overexpression counteracts the effects of miR-340-5p overexpression on inflammatory status in OGD/R-induced PC12 cells. (A) Neurod4 expression levels were analyzed in the different groups. Levels of the inflammatory markers (B) TNF- $\alpha$, (C) IL-6, (D) IL-1 $\beta$ and (E) MCP-1 were determined in the different groups. ${ }^{*} \mathrm{P}<0.05,{ }^{* *} \mathrm{P}<0.01,{ }^{* * *} \mathrm{P}<0.001$ vs. (A) empty plasmid or (B-E) OGD/R group; (B-E) ${ }^{\# \# \# ~} \mathrm{P}<0.001$ vs. OGD/R + miR-NC group; ${ }^{\Delta \Delta \Delta} \mathrm{P}<0.001$ vs. miR-340-5p mimic + empty plasmid group. IL, interleukin; MCP-1, monocyte chemoattractant protein-1; miR, microRNA; NC, negative control; Neurod4, neuronal differentiation 4; OGD/R, oxygen-glucose deprivation/reperfusion; TNF- $\alpha$, tumor necrosis factor $\alpha$.

miR-340-5p overexpression protects OGD/R-induced PC12 cells by reducing NO levels and increasing $p$-eNOS/eNOS expression levels, whereas this effect is counteracted by Neurod 4 overexpression. The OGD/R-induced increases in NO levels were significantly decreased in the OGD/R + miR-340-5p mimic group (Fig. 8A). However, the effect of miR-340-5p overexpression was significantly reversed following Neurod4 overexpression, suggesting that miR-340-5p overexpression may exert a protective effect by decreasing NO levels (Fig. 8A). The expression levels of p-eNOS were significantly increased in the OGD/R + miR-340-5p mimic group compared with the OGD/R group, but this effect was reduced following Neurod4 overexpression (Fig. 8B), indicating that miR-340-5p overexpression may protect $\mathrm{OGD} / \mathrm{R}$-induced $\mathrm{PC} 12$ cells from injuries by decreasing NO levels and the expression levels of p-eNOS/eNOS through downregulating Neurod4 expression.

\section{Discussion}

Ischemic stroke remains one of the major causes of morbidity; however, how to treat the condition remains largely unknown. The current therapeutic options for ischemic stroke are unsatisfactory; therefore, there is an urgent requirement to further study the underlying mechanisms to identify novel treatment options for ischemic stroke $(28,29)$. In the present study, miR-340-5p was observed to exert protective effects over OGD/R-induced PC12 cells through targeting Neurod4 expression. 
A

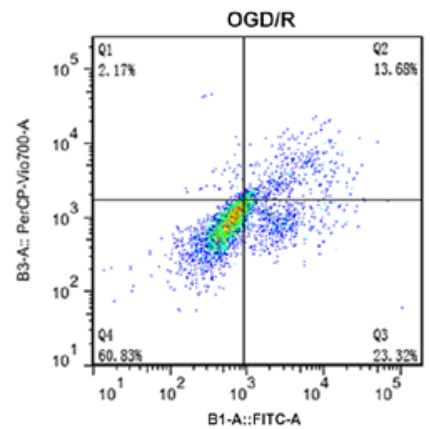

miR-340-5p mimic + empty plasmid
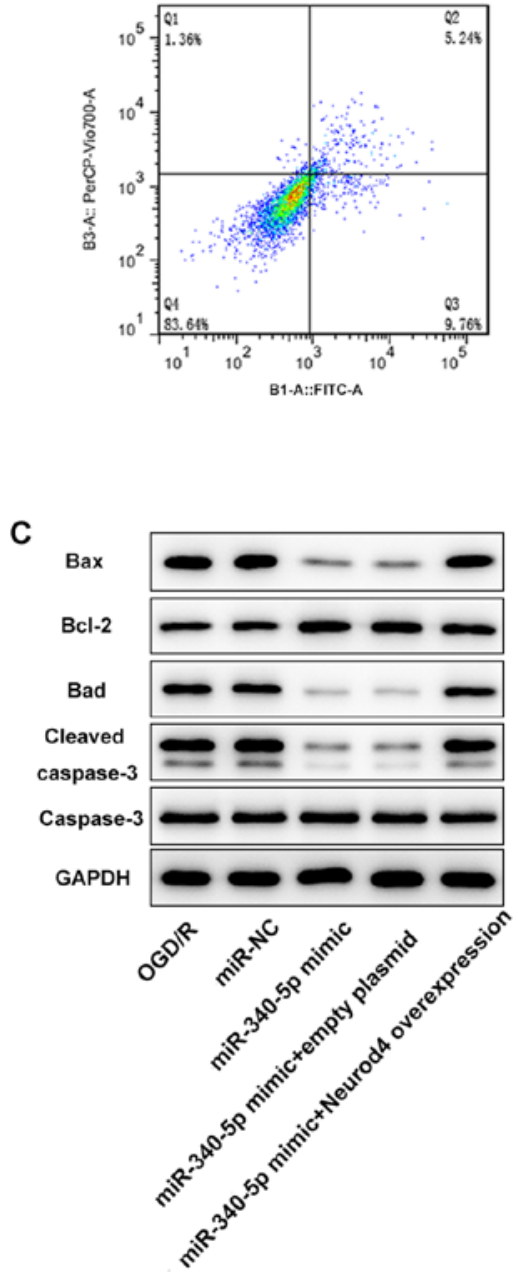
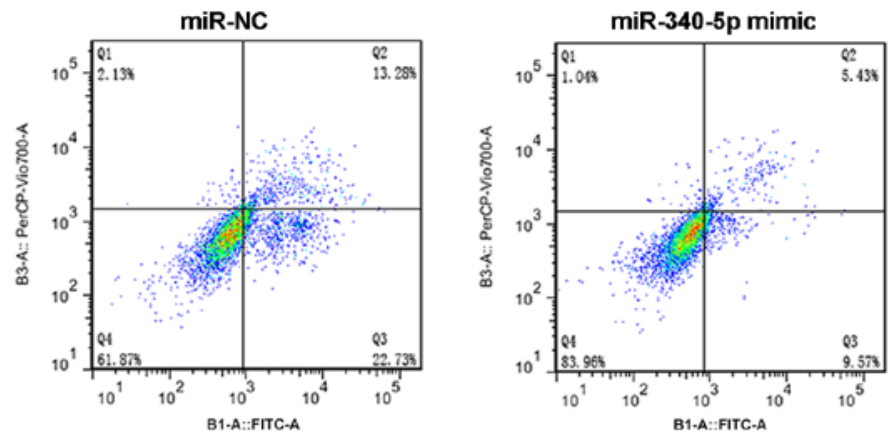

miR-340-5p mimic + Neurod4 overexpression
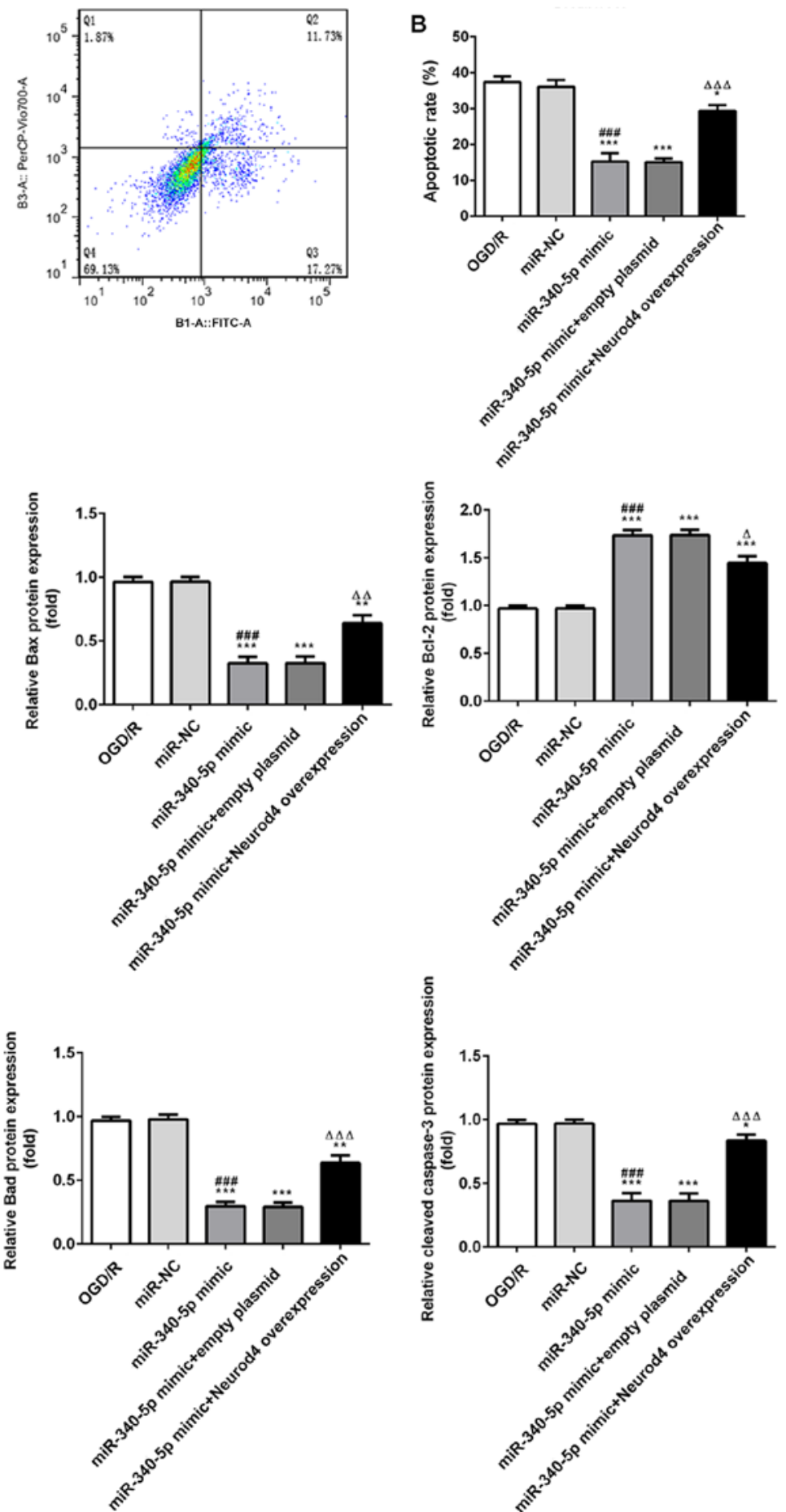

Figure 7. Neurod4 overexpression counteracts the effect of miR-340-5p overexpression on the apoptotic rate in OGD/R-induced PC12 cells. (A) Apoptotic rate was determined in the different groups. (B) Semi-quantification of (A). (C) Expression levels of Bax, Bcl-2, cleaved caspase and cleaved caspase 3 in

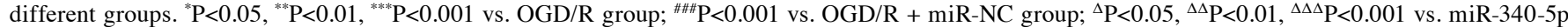
mimic + empty plasmid group. miR, microRNA; NC, negative control; Neurod4, neuronal differentiation 4; OGD/R, oxygen-glucose deprivation/reperfusion. 


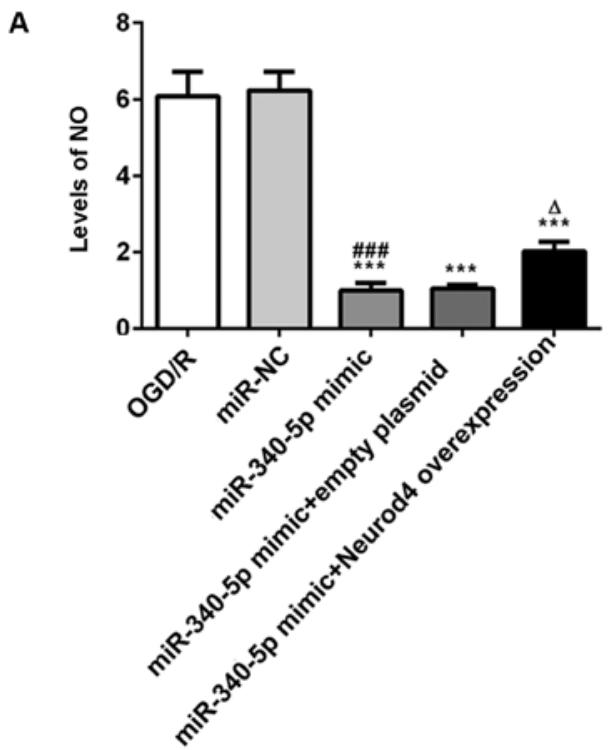

B

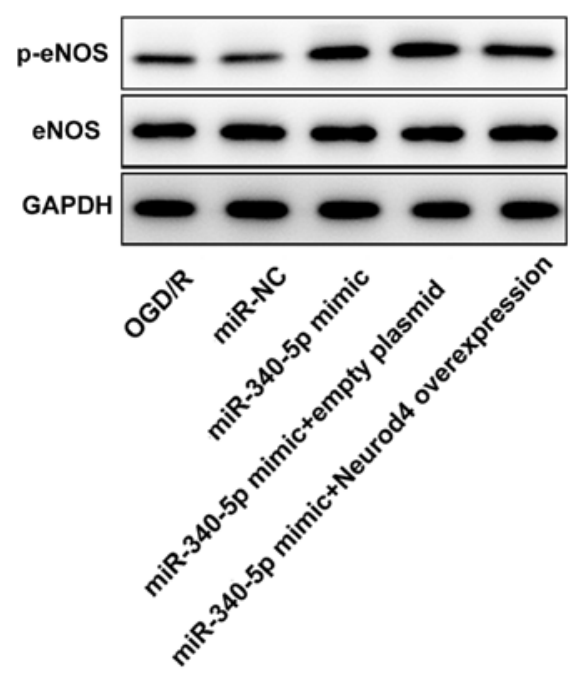

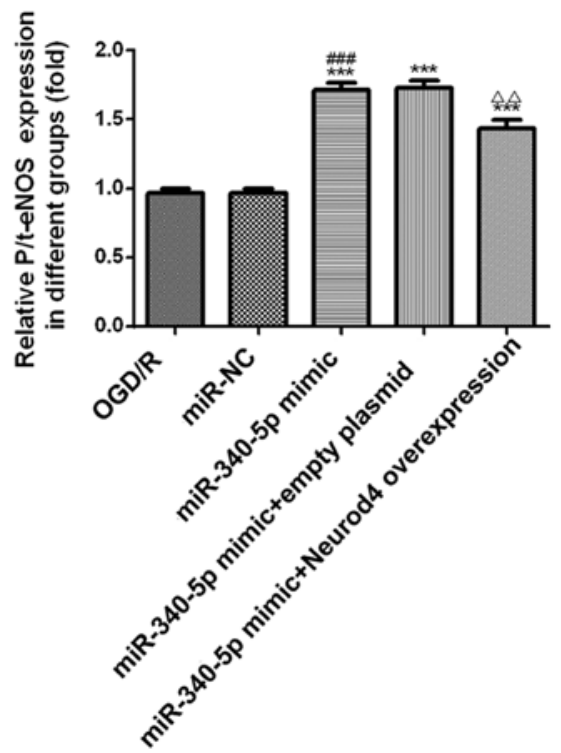

Figure 8. Neurod4 overexpression counteracts the effects of miR-340-5p overexpression on the levels of NO and the expression levels of p-eNOS/eNOS. (A) Levels of $\mathrm{NO}$ and (B) expression levels of $\mathrm{p}-\mathrm{eNOS} / \mathrm{eNOS}$ were detected in the different groups. ${ }^{* * * *} \mathrm{P}<0.001 \mathrm{vs}$. OGD/R group; ${ }^{\# \# "} \mathrm{P}<0.001 \mathrm{vs}$. OGD/R + miR-NC group; ${ }^{\Delta} \mathrm{P}<0.05,{ }^{\Delta} \mathrm{P}<0.01$ vs. miR-340-5p mimic + empty plasmid group. eNOS, endothelial nitric oxide synthase; miR, microRNA; NC, negative control; Neurod4, neuronal differentiation 4; NO, nitric oxide; OGD/R, oxygen-glucose deprivation/reperfusion; p, phosphorylated; $t$, total.

The insufficient presence of oxygen and glucose for normal metabolism is the main cause of injury in stroke (30) and as the therapeutic window is limited, early recanalization has proved helpful in preventing ischemic neuronal loss (31). Thrombolytic therapies are commonly used for the treatment of ischemic stroke (32); however, the recovery of blood flow has been found to promote secondary injuries (33). Thus, reducing reperfusion injuries is of great significance for improving the therapy available for ischemic stroke.

In the present study, $\mathrm{PC} 12$ cells that received OGD/R served as the cellular model, which has been used in numerous previous studies $(24,25,34,35)$. Consistent with the previous studies, the cell apoptotic rate, the inflammatory status and NO levels were increased following $\mathrm{OGD} / \mathrm{R}$ induction, indicating that the cellular model was successfully established $(36,37)$.

In a previous study, the expression levels of miR-340-5p were rapidly decreased in the peripheral blood of patients who had suffered from an acute ischemic stroke, which indicated a potentially protective role for miR-340-5p in ischemic stroke (22). Consistent with this previous study, miR-340-5p expression levels were decreased in the OGD/R group in the present study.

Cell apoptosis and inflammation are two important factors involved in ischemia-reperfusion injury (38-40). In the current study, following the overexpression of miR-340-5p in PC12 cells, the cell apoptotic rate, inflammatory status and NO levels induced by $\mathrm{OGD} / \mathrm{R}$ were reduced, providing validation for the protective role of miR-340-5p in cells induced by OGD/R.

Neurod4 is an important factor involved in neuronal differentiation; its expression levels have been reported to be increased under various stimuli, which was negatively correlated with the degree of neuron maturation (41). In the present study, Neurod4 was identified as a target gene of miR-340-5p. Neurod4 expression levels have also previously been reported to be increased following maternal hypoxia (42). In the present study, Neurod4 expression levels were increased in the OGD/R group compared with control group, and the OGD/R-induced 
increases in Neurod4 expression levels were reduced following miR-340-5p overexpression. To the best of our knowledge, the latter finding was reported for the first time in the present study, which suggested that miR-340-5p may protect PC12 cells from OGD/R injury through targeting Neurod4 expression. In addition, in a previous study, the inhibition of Neurod4 expression reduced the inflammatory levels and suppressed oxidative stress in spinal cord injury $(41,43)$. These injuries caused by inflammation and oxidative stress are suggested to be the two major factors involved in ischemia-reperfusion injury (40,44-46). In the present study, following Neurod4 overexpression, the apoptotic rate and inflammatory status of OGD/R-induced cells transfected with the miR-340-5p mimic were elevated. These findings suggested that the Neurod4 gene may be an important therapeutic target and targeting the Neurod4 gene with miR-340-5p may provide a novel strategy for treating ischemia-reperfusion injury. However, future studies are required to determine other targets that could be targeted for the treatment of ischemic stroke.

In a cerebral ischemia-reperfusion injury model, the levels of NO, a physiological messenger, were reported to be upregulated and the expression levels of p-eNOS/eNOS were decreased, which subsequently resulted in ischemia-reperfusion injuries (47). In the present study, increased levels of NO induced by $\mathrm{OGD} / \mathrm{R}$ were subsequently reduced following miR-340-5p overexpression. The opposite trend was observed to occur to the expression levels of p-eNOS/eNOS following miR-340-5p overexpression. Notably, the effects of miR-340-5p overexpression on NO levels and $\mathrm{p}$-eNOS/eNOS expression levels were reversed by Neurod4 overexpression. These findings further indicated that miR-340-5p may protect against injuries from $\mathrm{OGD} / \mathrm{R}$ through inhibiting the production of $\mathrm{NO}$ and increasing the expression levels of p-eNOS/eNOS through targeting Neurod4.

In conclusion, the findings of the present study suggested that miR-340-5p may exert protective effects over OGD/R in PC12 cells through targeting Neurod4 expression. These results may provide novel strategies for alleviating the injuries obtained from ischemia-reperfusion and pave the way for future research on ischemia-reperfusion injury.

\section{Acknowledgements}

Not applicable.

\section{Funding}

No funding was received.

\section{Availability of data and materials}

The datasets used and/or analyzed during the current study are available from the corresponding author on reasonable request.

\section{Authors' contributions}

JW designed the present study, prepared the manuscript and was involved in performing the experiments. GL performed some parts of the experiments and helped to design the study. Both authors read and approved the final manuscript.

\section{Ethics approval and consent to participate}

Not applicable.

\section{Patient consent for publication}

Not applicable.

\section{Competing interests}

The authors declare that they have no competing interests.

\section{References}

1. Satue E, Vila-Corcoles A, Ochoa-Gondar O, de Diego C, Forcadell MJ, Rodriguez-Blanco T, Barnes L and Jariod M: Incidence and risk conditions of ischemic stroke in older adults. Acta Neurol Scand 134: 250-257, 2016.

2. Lozano R, Naghavi M, Foreman K, Lim S, Shibuya K, Aboyans V, Abraham J, Adair T, Aggarwal R, Ahn SY, et al: Global and regional mortality from 235 causes of death for 20 age groups in 1990 and 2010: A systematic analysis for the global burden of disease study 2010. Lancet 380: 2095-2128, 2012.

3. Zhang Q, Wang Y, Song H, Hou C, Cao Q, Dong K, Huang X, Feng W, Ovbiagele B, Wang M and Ji X: Clopidogrel and ischemic stroke outcomes by smoking status: Smoker's paradox? J Neurol Sci 373: 41-44, 2017.

4. Alloubani A, Saleh A and Abdelhafiz I: Hypertension and diabetes mellitus as a predictive risk factors for stroke. Diabetes Metab Syndr 12: 577-584, 2018.

5. Gao Y, Li R, Sun H, Li J, He B, Xiao S, Li L and Wang J: Protective effects of oroxylin a on oxygen-glucose deprivation/reperfusion-induced $\mathrm{PC} 12$ cells by activating the sonic hedgehog signal pathway. Nat Product Commun 14: 1934578X19881544, 2019.

6. Huang J, Upadhyay UM and Tamargo RJ: Inflammation in stroke and focal cerebral ischemia. Surg Neurol 66: 232-245, 2006.

7. Peyravian N, Dikici E, Deo S, Toborek M and Daunert S: Opioid antagonists as potential therapeutics for ischemic stroke. Prog Neurobiol 182: 101679, 2019.

8. Yue XY, Feng ZQ, Yu XY, Hu JM, He XJ and Shu S: Fire-needle acupuncture for upper limb spastic paralysis after stroke: Study protocol for a randomized controlled trial. J Integr Med 17: 167-172, 2019.

9. Barthels D and Das H: Current advances in ischemic stroke research and therapies. Biochim Biophys Acta Mol Basis Dis 1866: 165260, 2020.

10. Farzaneh M, Alishahi M, Derakhshan Z, Sarani NH, Attari F and Khoshnam SE: The expression and functional roles of miRNAs in embryonic and lineage-specific stem cells. Curr Stem Cell Res Ther 14: 278-289, 2019.

11. Yin KJ, Deng Z, Hamblin M, Xiang Y, Huang H, Zhang J, Jiang X, Wang Y and Chen YE: Peroxisome proliferator-activated receptor delta regulation of miR-15a in ischemia-induced cerebral vascular endothelial injury. J Neurosci 30: 6398-6408, 2010.

12. Liu P, Zhao H, Wang R, Wang P, Tao Z, Gao L, Yan F, Liu X, Yu S, Ji X and Luo Y: MicroRNA-424 protects against focal cerebral ischemia and reperfusion injury in mice by suppressing oxidative stress. Stroke 46: 513-519, 2015.

13. Xu LJ, Ouyang YB, Xiong X, Stary CM and Giffard RG: Post-stroke treatment with miR-181 antagomir reduces injury and improves long-term behavioral recovery in mice after focal cerebral ischemia. Exp Neurol 264: 1-7, 2015.

14. Harraz MM, Eacker SM, Wang X, Dawson TM and Dawson VL: MicroRNA-223 is neuroprotective by targeting glutamate receptors. Proc Natl Acad Sci USA 109: 18962-18967, 2012.

15. Gao L, Pu X, Huang Y and Huang J: MicroRNA-340-5p relieved chronic constriction injury-induced neuropathic pain by targeting Rap1A in rat model. Genes Genomics 41: 713-721, 2019.

16. Li D, Zhou J, Yang B and Yu Y: microRNA-340-5p inhibits hypoxia/reoxygenation-induced apoptosis and oxidative stress in cardiomyocytes by regulating the Act1/NF-kB pathway. J Cell Biochem 120: 14618-14627, 2019. 
17. Long M, Wang Z, Zheng D, Chen J, Tao W, Wang L, Yin N and Chen Z: Electroacupuncture pretreatment elicits neuroprotection against cerebral ischemia-reperfusion injury in rats associated with transient receptor potential vanilloid 1-mediated anti-oxidant stress and anti-inflammation. Inflammation 42 : 1777-1787, 2019.

18. Dai Y, Zhang H, Zhang J and Yan M: Isoquercetin attenuates oxidative stress and neuronal apoptosis after ischemia/reperfusion injury via Nrf2-mediated inhibition of the NOX4/ROS/NF-kB pathway. Chem Biol Interact 284: 32-40, 2018.

19. Jiang Y, Li L, Tan X, Liu B, Zhang Y and Li C: miR-210 mediates vagus nerve stimulation-induced antioxidant stress and anti-apoptosis reactions following cerebral ischemia/reperfusion injury in rats. J Neurochem 134: 173-181, 2015.

20. Palencia G, Medrano JAN, Ortiz-Plata A, Farfán DJ, Sotelo J, Sánchez A and Trejo-Solís C: Anti-apoptotic, anti-oxidant, and anti-inflammatory effects of thalidomide on cerebral ischemia/reperfusion injury in rats. J Neurol Sci 351: 78-87, 2015.

21. Saad MA, Abdelsalam RM, Kenawy SA and Attia AS: Ischemic preconditioning and postconditioning alleviates hippocampal tissue damage through abrogation of apoptosis modulated by oxidative stress and inflammation during transient global cerebral ischemia-reperfusion in rats. Chem Biol Interact 232: 21-29, 2015.

22. Yoo H, Kim J, Lee AR, Lee JM, Kim OJ, Kim JK and Oh SH: Alteration of microRNA 340-5p and arginase-1 expression in peripheral blood cells during acute ischemic stroke. Mol Neurobiol 56: 3211-3221, 2019

23. Zhu H, Wang X and Chen S: Downregulation of MiR-218-5p protects against oxygen-glucose deprivation/reperfusion-induced injuries of PC12 cells via upregulating n-myc downstream regulated gene 4 (NDRG4). Med Sci Monit 26: e920101, 2020.

24. Shu K and Zhang Y: Protodioscin protects $\mathrm{PC} 12$ cells against oxygen and glucose deprivation-induced injury through miR-124/AKT/Nrf2 pathway. Cell Stress Chaperones 24 1091-1099, 2019.

25. Wang JK, Wang LC, Jiang Y, Tu PF and Zeng KW: Neuroprotective effects and mechanism of ethanol extract of cistanche tubulosa against oxygen-glucose deprivation/reperfusion. Zhongguo Zhong Yao Za Zhi 44: 2686-2690, 2019 (In Chinese).

26. Livak KJ and Schmittgen TD: Analysis of relative gene expression data using real-time quantitative PCR and the 2(-Delta Delta C(T)) method. Methods 25: 402-408, 2001

27. Kovac S, Angelova PR, Holmstrom KM, Zhang Y, Dinkova-Kostova AT and Abramov AY: Nrf2 regulates ROS production by mitochondria and NADPH oxidase. Biochim Biophys Acta 1850: 794-801, 2015.

28. Li H, Ma J, Fang Q, Li H, Shen H, Li X, Xue Q, Zhu J and Chen G: Botch protects neurons from ischemic insult by antagonizing Notch-mediated neuroinflammation. Exp Neurol 321: 113028, 2019

29. Urdaneta AE and Bhalla P: Cutting edge acute ischemic stroke management. Emerg Med Clin North Am 37: 365-379, 2019.

30. Geng J, Zhang Y, Li S, Wang J, Wang H, Aa J and Wang G: Metabolomic profiling reveals that reprogramming of cerebral glucose metabolism is involved in ischemic preconditioning-induced neuroprotection in a rodent model of ischemic stroke. J Proteome Res 18: 57-68, 2019.

31. Cisse FA, Damien C, Bah AK, Touré ML, Barry M, Djibo Hamani AB, Haba M, Soumah FM and Naeije G: Minimal setting stroke unit in a sub-saharan African public hospital. Front Neurol 10: 856, 2019.

32. Moussaddy A, Demchuk AM and Hill MD: Thrombolytic therapies for ischemic stroke: Triumphs and future challenges. Neuropharmacology 134: 272-279, 2018.

33. Piccardi B, Arba F, Nesi M, Palumbo V, Nencini P, Giusti B, Sereni A, Gadda D, Moretti M, Fainardi E, et al: Reperfusion injury after ischemic stroke study (RISKS): Single-centre (Florence, Italy), prospective observational protocol study. BMJ Open 8: e021183, 2018.
34. Li Y, Shi J, Sun X, Li Y, Duan Y and Yao H: Theaflavic acid from black tea protects PC12 cells against ROS-mediated mitochondrial apoptosis induced by OGD/R via activating Nrf2/ARE signaling pathway. J Nat Med 74: 238-246, 2020.

35. Liu Y, Wu X, An J, Lv W, Geng Y, Lou T and Zhang Y Glaucocalyxin B protects against oxygen-glucose-deprivation/reperfusion-induced neuronal injury in PC-12 cells. J Cell Biochem 120: 6137-6144, 2019.

36. Yu Y, Zhang X, Han Z, Zhao W and Zhang L: Expression and regulation of miR-449a and AREG in cerebral ischemic injury. Metab Brain Dis 34: 821-832, 2019.

37. Wang H, Wei W, Lan X, Liu N, Li Y, Ma H, Sun T, Peng X, Zhuang $\mathrm{C}$ and $\mathrm{Yu} \mathrm{J}$ : Neuroprotective effect of swertiamain on cerebral ischemia/reperfusion injury by inducing the Nrf2 protective pathway. ACS Chem Neurosci 10: 2276-2286, 2019.

38. Huang XP, Ding H, Lu JD, Tang YH, Deng BX and Deng CQ Autophagy in cerebral ischemia and the effects of traditional Chinese medicine. J Integr Med 13: 289-296, 2015.

39. Nan L, Xie Q, Chen Z, Zhang Y, Chen Y, Li H, Lai W, Chen Y and Huang M: Involvement of PARP-1/AIF signaling pathway in protective effects of gualou guizhi decoction against ischemia-reperfusion injury-induced apoptosis. Neurochem Res 45 : 278-294, 2020.

40. Wicha P, Tocharus J, Janyou A, Jittiwat J, Changtam C, Suksamrarn A and Tocharus C: Hexahydrocurcumin protects against cerebral ischemia/reperfusion injury, attenuates inflammation, and improves antioxidant defenses in a rat stroke model. PLoS One 12: e0189211, 2017.

41. Yang L, Ge D, Chen X, Jiang C and Zheng S: miRNA-544a regulates the inflammation of spinal cord injury by inhibiting the expression of NEUROD4. Cell Physiol Biochem 51: 1921-1931, 2018.

42. Golan MH, Mane R, Molczadzki G, Zuckerman M, Kaplan-Louson V, Huleihel M and Perez-Polo JR: Impaired migration signaling in the hippocampus following prenatal hypoxia. Neuropharmacology 57: 511-522, 2009.

43. Dai J, Xu LJ, Han GD, Sun HL, Zhu GT, Jiang HT, Yu GY and Tang XM: MiR-137 attenuates spinal cord injury by modulating NEUROD4 through reducing inflammation and oxidative stress. Eur Rev Med Pharmacol Sci 22: 1884-1890, 2018.

44. Gao XJ, Xie GN, Liu L, Fu ZJ, Zhang ZW and Teng LZ: Sesamol attenuates oxidative stress, apoptosis and inflammation in focal cerebral ischemia/reperfusion injury. Exp Ther Med 14: 841-847, 2017.

45. Zhang DD, Zou MJ, Zhang YT, Fu WL, Xu T, Wang JX, Xia WR Huang ZG, Gan XD, Zhu XM and Xu DG: A novel IL-1RA-PEP fusion protein with enhanced brain penetration ameliorates cerebral ischemia-reperfusion injury by inhibition of oxidative stress and neuroinflammation. Exp Neurol 297: 1-13, 2017.

46. Jiang M, Li J, Peng Q, Liu Y, Liu W, Luo C, Peng J, Li J, Yung KK and Mo Z: Neuroprotective effects of bilobalide on cerebral ischemia and reperfusion injury are associated with inhibition of pro-inflammatory mediator production and down-regulation of JNK1/2 and p38 MAPK activation. J Neuroinflammation 11: 167,2014

47. He D, Song X and Li L: Geranylgeranylacetone protects against cerebral ischemia and reperfusion injury: HSP90 and eNOS phosphorylation involved. Brain Res 1599: 150-157, 2015.

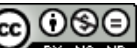

This work is licensed under a Creative Common Attribution-NonCommercial-NoDerivatives 4.0 International (CC BY-NC-ND 4.0) License. 